\title{
ANTIVENOM FOR SNAKE BITE: CRITICAL SUPPLY IN HEALTH CARE SETTINGS
}

\author{
MD. ROBED AMIN
}

\begin{abstract}
Poisonous snake bite is common in Bangladesh, especially on the countryside. Often fatality occurs in these cases due to lack of anti-snake venom supply in rural areas. Health professionals are sometimes found wanting in skills and knowledge in dealing with such cases. Critical care support is essential in every case of snake bite which, unfortunately, is underdeveloped in our country. We are in urgent need of locally produced anti-snake venom to ensure availability of this life-saving drug in all parts of the country.
\end{abstract}

Keyword: Anti-snake venom, Bangladesh

Envenoming by snakes is an occupational health hazard often faced by farmers and farm laborers of tropical and subtropical countries like Bangladesh. Snake bite is frequently accidental, faced mostly by rural people. The high fatality rate due to venomous snake bite (around 20\%) remain largely unnoticed and not appropriately managed by medical professionals. ${ }^{1}$ Lack of awareness of junior doctors regarding scientific treatment of snake bite recommended by national guideline further delays proper treatment of victims.

There are about 82 species of snakes identifiable in Bangladesh of which 28 are known venomous. The major venomous snakes in Bangladesh are Elapidae which includes common cobra (Naja kauthia and Naja naja), king cobra and common krait (Bungarus caerulus), uncommon kraits (Bungarus niger, Bugarus wali, viperidae includes Russell's viper, and pit viper and hydrophidae (the sea snakes). ${ }^{2}$ During monsoon season or during flooding fatal snake bite usually comes to notice through media .Surprisingly urban case of venomous snake bites were observed in Dhaka Medical College of Hospital during last large flooding in 2004. Early rapid neurotoxic manifestations are seen in cobra bite with local envenoming and occasionally with or without fang mark. Though krait venom is ten times more lethal than cobra, delayed clinical effects are due to slow absorption of venom being deposited in skin deep or subcutaneous tissue by short and sharp fangs. ${ }^{3}$

Anti- snake venom (ASV) is a specific antidote for venomous snakebite. ASV is most effective when used in appropriate dosage and appropriate indication. Although its efficacy is of no doubt, there is high risk of development of anaphylaxis. Hence ASV should be used only in an indicated case in proper dosage to prevent crisis of its supply. ${ }^{3,4}$ Bangladesh has no venom laboratory (commercial) for extraction of venom or preparing anti-snake venom. There are no pharmaceuticals companies in Bangladesh who have come forward to manufacture this vital medicine. So we turned to India for supplying the ASV as a part of disaster management.

There is no complete national data of snake bite cases in Bangladesh although recently a large survey is being carried out for identifying case load. It is estimated that 4.3 person per 100,000 population are the victims of snake bite in Bangladesh. ${ }^{5}$ In Bangladesh polyvalent ASV is available which contain antibody against cobra, Russell's viper, common krait and saw-scaled viper. It has no role against uncommon kraits, pit vipers and sea snakes. Exact total amount of venom injected by a snake at the time of bite is unknown but fatal dose is known

viz. cobra 120 mg, Russell's viper 150 mg, krait 60 $\mathrm{mg}$. The amount of venom neutralized by one $\mathrm{ml}$ of

Correspondence: Dr. Md. Robed Amin, Assistant Professor, Department of Medicine, Dhaka Medical College, E-mail: robedamin@yahoo.com 
polyvalant ASV is known viz. cobra $0.6 \mathrm{mg}$, Russell's viper $0.6 \mathrm{mg}$, krait $0.45 \mathrm{mg}$. So empirically total ASV required is 200, 250, 134 respectively. However, the clinical features and outcomes are not as simple as predicted, because every bite does not result in complete envenomation. ${ }^{6}$ In Bangladesh commercially produced ASV is not licensed but medicine shops still sell the medicine which comes through black-marketing and the price is very high( a single dose cost about 6000 Taka. The Government purchases the ASV very cheaply from India but doesn't have consistent supply in adequate amount. Majority of snake bite victims report to government hospitals because ASV is given free-of-cost. Most of the victims delay attending hospital and vital time is lost by attending to ojha and others before critical respiratory problem arises.

Medical officers are not well trained through guideline in our country and has no experience in dealing cases of snake bite before. ${ }^{7} \mathrm{ASV}$ is utilized poorly due to lack of experience and training. Many times it is avoided in an indicated case due to fear of anaphylaxis but administered to patients when there is no indication. ${ }^{7}$

Though the dose of ASV is not fixed, the indications are known. ${ }^{3}$ In our country, empirical dose needed for cobra bite is around 100-200 ml and for krait it is around 300-400 ml. Although a Russel's viper bite needs around 100-800 $\mathrm{ml}$ of ASV, it is not a common venomous snake in Bangladesh and report of such viperidae is just matter of academic interest. ${ }^{8}$ There is Micro-Elisa kit for detection of snake venom and venom antibody which help us to know the exact circulating venom and need of ASV. 9,10 This will be of great value in a country like Bangladesh where snake bite is endemic and ASV is always in short supply. ASV neutralizes the circulating venom only and no amount of ASV will neutralize or combine with venom once the venom is attached or adsorbed to target organs i.e. platelets, RBCs, vascular endothelium, renal tubules, muscles and neuromuscular receptors. Early administration of ASV prevents the target organ damage. ${ }^{11,12}$ Damaged organs can be salvaged by routine management protocol. ${ }^{12}$ Half-life of ASV varies between 26-96 hours, whereas antigen (venom) may reappear in circulation after as long as 130 hours. ${ }^{13}$ The dose of polyvalent ASV needed to neutralize snake venom in many snakes is very high which increases the chance of anaphylaxis. Reduction of requirement of ASV can be achieved by preparing ASV from venoms obtained from snakes caught from relevant areas of the country. ${ }^{12}$ The next question arises-is ASV is essential for management of snake envenoming?

In a situation of non-availability of ASV, many cases had recovered with blood transfusion alone. ${ }^{14}$ Those cases allergic to ASV recovered with conservative measures i.e. ventilator, blood transfusion, anticholinesterase, thrombin inhibitors, fibrinolytic agents, peritoneal dialysis and inotropes may speed up the recovery. ${ }^{15-18}$ The experience of nonavailability of ASV and managing with other measures have also saved few lives in our country but overall outcome was not as good as when ASV is available. Preparation of safe mono-specific ovine FAB fragment antivenom is more effective and potent and may help to fulfill the requirement of ASV. ${ }^{19}$

Training in appropriate use of ASV according to national guideline should be arranged at all hospital level to ease the crisis of supply of ASV. Early administration of ASV prevents morbidity and mortality. The government should take appropriate steps to ensure constant supply of ASV in our health facility. The training for doctors through national guideline is crucial for management of such cases. The pharmaceuticals companies of our country should take immediate initiatives for manufacturing ASV. We need snake farm development in our country like Thailand, India etc for our enrichment of venoms. Venom laboratory and manufacturing monovalent ASV by identification of venom specific snake species of Bangladesh is the long term solution of this particular non- communicable endemic disease.

\section{References}

1. Faiz MA, Rahman MR, Das JC. Neurotoxicity and tissue necrosis following bite by cobra (Naja), 1994, Dhaka Congress.

2. Sarker MSU, Sarker NJ, Patwary MS (1999). Epidemiological Survey of Snake Bite Incidence in Bangladesh. Report submitted to Ministry of Science and Technology, Bangladesh Government, Dhaka.

3. Warrell DA. The clinical managerment of snake bites in the Southeast Asian region. Southeast Asian J Trop Med Public Health 1999;30:1-84. 
4. Theakston RDG, Warrell DA. Crisis in snake antivenom supply for Africa. Lancet 2000;356:2104.

5. Faiz MA, et al. Non-poisonous snake bite in Chittagong Medical College Hospital. Bangladesh Medical Journal 1999; 28(1,2): 3-4.

6. Reid HA. Animal poisons. In: Manson Bahr PEC, Apted FIC, eds. Manson's Tropical Diseases, $18^{\text {th }}$ ed. London:Balliere-Tindall 1982:544-6.

7. Bawskar HS, Bawaskar PH. Call for global snakebite control and procurement funding. Lancet 2001;357:1132-33.

8. Faiz MA, Chowdhury SK, Hussain I. Snake Bite in Chittagong and Cox's bazar - a Hospital Based Study. Bangladesh J Medicine 1997;8:52-57.

9. Theakston RDG, Phillips RE, Warrell DA, et al. Envenoming by the common krait and Sri Lankan cobra : efficacy and complications of therapy with Haffkine anti-venom. Trans Roy Soc Trop Med And Hyg 1990;84:301- 08.

10. Theakston RDG, Lloyd-Jones J, Reid HA. MicroELISA for detecting and assaying snake venom and venom -antibody. Lancet 1977;II:639-41.

11. Warrell DA. Venomous bites and sting. Medicine International 1992;4529-33.
12. Bawaskar HS and Bawaskar PH. Profile of snakebite envenoming in western Maharashtra, India. Trans Roy Soc Trop Med Hyg 2002;96:79-84.

13. Reid HA, Chan KE, Thean PC. Prolonged coagulation defect (defibrination syndrome) in Malayan viper bite. Lancet 1963,I:621-26.

14. Bhat RN. Viperine snake bite poisoning in Jammu. J Ind Med Assoc 1974;63:383-92.

15. Paul V, Pratibha, Prahalad KS, et al. High dose anti-snake venom versus low dose anti-snake venom in the treatment of poisonous snake bites- A critical study. JAPI 2004;52:14-7.

16. Reid HA. E-aminocaproic acid and fibrimnolysis in viper -bite defibrination syndrome. Lancet 1965;I:5-7.

17. Bomb BS, Roy S, Kumawat DC, Bharjatya M. Do we need anti-snake venom for management of elapid ophitoxaemia. JAPI 1996;44;31-33.

18. Paul V, Prahld KA, Earali J, et al. Trial of Heparin in viper bites. JAPI 2003;51:163-66.

19. Araratnam CA, Meyer WP, Perera G, et al. A new monospecific ovine FAB fragment antivenom for treatment of envenoming by the SRI Lankan Russell's viper : a preliminary dose -finding and pharmacokinetic study. Am J Trop Med Hyg 1999;61:259-65. 